ask you all to help us and we will try then to sample these things and perhaps next year the sexual problem will be again subject of our meeting at Stoke Mandeville.

Chairman. Thank you, Dr. Paeslack, and I am sure that this will be a fruitful project for the Society to undertake. As Professor Jochheim said last night, one of the things that he finds so attractive about this Society is that we are all putting our subject higher than our individualities and we are not worried about whose name goes on a paper-we are interested in exploration of a subject, and these words struck home to me as being a very fair expression of the feelings of the majority.

\title{
TRACHEAL STENOSIS FOLLOWING TRACHEOSTOMY
}

By H. L. Frankel, M.B.; M.R.C.P.

National Spinal Injuries Centre, Stoke Mandeville Hospital

TRACHEAL stenosis following tracheostomy and intermittent positive pressure respiration (I.P.P.R.) has been described by Gibson (1967) and in tetraplegic patients following tracheostomy and intermittent positive pressure respiration by Frankel (1968). We have now seen this serious complication in a total of four patients. As tracheostomy is quite frequently performed in traumatic paraplegia and tetraplegia, I thought it would be worth while to describe these cases in more detail.

\section{CLINICAL DETAILS}

The main findings in these patients are shown in Table I. Three of the patients had cervical cord lesions and one had a cauda equina lesion, I.P.P.R. being needed

TABLE I

\begin{tabular}{|c|c|c|c|c|c|c|}
\hline Patient & Age & Sex & $\begin{array}{l}\text { Neurological lesion and } \\
\text { reason for tracheostomy }\end{array}$ & $\begin{array}{l}\text { Duration of } \\
\text { I.P.P.R. }\end{array}$ & $\begin{array}{l}\text { Time between } \\
\text { tracheostomy } \\
\text { and diagnosis } \\
\text { of stenosis }\end{array}$ & $\begin{array}{l}\text { Main clinical } \\
\text { feature }\end{array}$ \\
\hline I & I8 & M & $\begin{array}{l}\text { Fracture dislocation C5. } \\
\text { Required I.P.P.R. }\end{array}$ & 4 months & 4 months & $\begin{array}{l}\text { Expiratory } \\
\text { wheezing } \\
\text { cyanosis }\end{array}$ \\
\hline 2 & I4 & $\mathrm{F}$ & $\begin{array}{c}\text { Encephalomyelitis } \\
\text { Required I.P.P.R. }\end{array}$ & Io days & 4 months & Asthma cyanosis \\
\hline 3 & $4 \mathrm{I}$ & M & $\begin{array}{l}\text { Fracture Li. 'Stove-in' } \\
\text { chest }\end{array}$ & I5 days & $\begin{array}{l}5 \text { weeks } \\
\text { (5 days after } \\
\text { extubation) }\end{array}$ & Stridor cyanosis \\
\hline 4 & 22 & M & $\begin{array}{l}\text { Fracture dislocation C6. } \\
\text { Required I.P.P.R. }\end{array}$ & 2 days & $\begin{array}{l}3 \text { months } \\
\text { (I weekafter } \\
\text { extubation) }\end{array}$ & Stridor cyanosis \\
\hline
\end{tabular}


for management of his associated chest injuries. In all cases cuffed 'Portex' tracheostomy tubes were used. In the first two patients the cuff was deflated for five minutes every two hours, in the last two patients for five minutes at hourly intervals. The amount of air injected into the cuff was decided by the doctor using just enough to produce a good 'seal'-this amount never exceeded 8 c.c.

Patient No. I nearly died before the diagnosis was made; up to that point I thought he was suffering from status asthmaticus and had treated him with corticosteroids. The site of the stenosis was near the position of the end of the tracheostomy tube. The trachea was dilated with bougies and he is now dependent on long-term use of size 34 ChevalierJackson silver tracheostomy tube. This has now been used for three years and every attempt to remove the tube has been followed by a recurrence of the obstruction within a few hours.

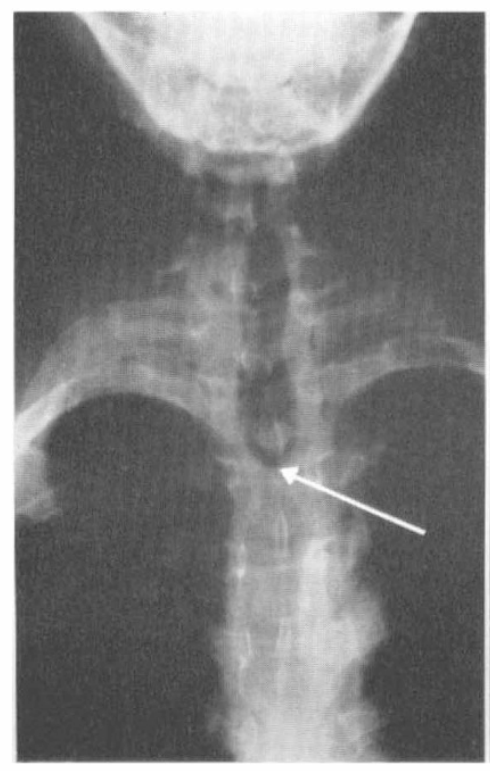

FIG. I

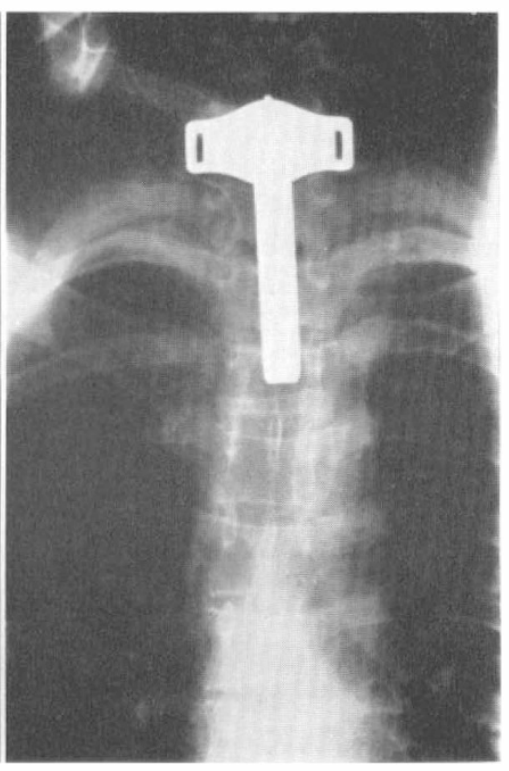

FIG. 2

Patient No. 2 had made a nearly complete recovery from her neurological lesion and her tracheostomy had been closed when symptoms of respiratory obstruction occurred. Again this seemed at first to be bronchial asthma, particularly as the patient had suffered from asthma in the past. She also was treated with corticosteroid drugs. When the obstruction was recognised she also was in extremis. The trachea was held open with rubber tubes and each time the tubes were removed the obstruction recurred within a few hours. Finally, I5 months after the original tracheostomy, Mr. G. Grimshaw operated; he found dense fibrous tissue around the stenosis; when this had been disected out the irregular stricture was excised and the cut ends of the trachea were approximated with interrupted sutures. The initial progress was good but she died on the 5 th postoperative day due to rupture of the innominate artery into the trachea.

Patient No. 3. This patient had a cauda equina lesion and severe associated chest injuries. He was on I.P.P.R. for two weeks and the tracheostomy was allowed to close after four weeks. Five days later he developed stridor and cyanosis. The trachea was 
dilated with bougies and a size 34 Chevalier-Jackson tracheostomy tube inserted. This tube was removed after one month. The stenosis recurred. The trachea was again dilated with difficulty. He continued with the Chevalier-Jackson tube for another five months. The tube was removed then and the tracheostomy allowed to close. He remains well one year later.

Patient No. 4 was only on I.P.P.R. for two days. Within a few days we suspected some tracheal pathology but a definite diagnosis was only made 3 months later. A week after the tracheostomy had been closed on X-ray showed the stenosis (fig. I). The trachea was dilated with bougies and a size 34 Chevalier-Jackson tube inserted (fig. 2). Several attempts to remove this tube failed, the obstruction recurred within a few days. The stenosis was excised one year after the original injury by Mr. Grimshaw. One month after the operation the tracheostomy is closed and the patient's condition is good.

The two operated cases showed dense fibrous tissue. In the early stages the obstruction seemed to be due to granulation tissue and collapse of the trachea, possibly due to necrosis of tracheal cartilage.

\section{DISCUSSION}

Gibson (1967) considered that over-inflation of the cuff, movement of the tracheostomy tube with each stroke of the respirator and secondary infection were the main causes of the stenosis. Bannister and Braver (1969) stressed the danger of the relatively hard 'Protex' tracheostomy tubes and Crampton Smith et al. (I969) pointed out that they had found no case of low tracheal stenosis in a large series and in their Unit only soft rubber tracheostomy tubes were used.

In the National Spinal Injuries Centre we used rubber cuffed tracheostomy tubes of the 'Oxford' type until 1965, when we started to use the plastic 'Portex' cuffed tube. This tube seemed to have several advantages. It was disposable, pre-sterilised, smooth-walled and easy to change. It was preferred by nurses and patients. Within a year of starting to use these tubes we had our first two cases of low tracheal stenosis. It seems likely from our four cases that the type of tube is at least partly to blame, possibly due to the relative rigidity of the tube or to the localised pressure exerted by the cuff as opposed to the much longer area of contact with the 'Oxford' tube. Because of the serious and potentially fatal nature of this complication we are again using rubber cuffed tracheostomy tubes as a routine.

Acknowledgments. I am grateful to Mr. G. Grimshaw, Mr. W. McN. Niblock and Dr. N. Welply for their help in treating these patients.

\section{REFERENCES}

Bannister, R. \& Beaver, R. A. (I969). Brit. Med. F. 2, I85. CRAmpton SMith A., KeRR, J. H. \& Spalding, M. K. (I969). Brit. med. F. 2, 383. Frankel, H. L. (1968). Int. F. Paraplegia, 5, $22 \mathrm{I}$. Gibson, P. (1967). Thorax, 22, I.

\section{ADDENDUM}

Since this paper was read, patient No. 4 has remained well with no recurrence of the stenosis and patient No. I has had the stenosis resected by Mr. Grimshaw and is well three months after the operation. 


\section{Discussion}

D. HANCOCK (G.B.). Over a personal series of about 70 tracheostomies and an observed number of probably well over three times that in a practice extending over I I years I have only seen one stenosis, and this was in a polythene-type tracheostomy tube. The other ones were both rubber and polythene and all inflated at times and certainly not let down as frequently as those in this hospital. I think that Dr. Frankel's acute incidence of this relatively large number of acute stenosis happening recently, points very strongly to a change in design of catheters and I think we must look both at the fact that the balloon inflates eccentrically and perhaps a change in the chemical constituents used to cure the polythene in its formation.

T. McSweEney (G.B.). The remarks have no special reference to Dr. Frankel's case, because I am quite certain there was a valid indication for tracheostomy. The only point I would like to raise, and I have mentioned it at this Society and others before, is, I think, you must ask: is your tracheostomy really necessary. There is a sort of thinking even in our own Society and certainly in people who deal with head injuries, that because a person is admitted unconscious he must therefore have a tracheostomy, without considering the possibility of a temporary, that is a 24 -hour, endotracheal intubation. And you can get the endotracheal tube now which will harness to an intermittent positive pressure machine with a cylindrical rather than a balloon-like blockage agent. We find that the need drops as the quality of the physiotherapy available improves. The last point I should make is that, as Dr. Frankel pointed out, reconstructive surgery for these conditions is a most hazardous and terrifying business. So that, if we can avoid it, obviously even to the extent of temporising on endotracheal intubation for a short time, I think there is a virtue in it.

Sir Ludwig Guttmann. I entirely agree with Mr. McSweeney, that before we think of a tracheostomy one should try to make an intubation. This is the less harmful and will not as easily produce a pressure sore, as I think that this is a cause of the stenosis. These people with high cervical lesions are anaesthetic, and moreover, the tone of the tracheal mucosa is lowered, resulting in lowering of resistance of the tissues to pressure. That is a point I wanted to make, to consider how far by our manipulation during tracheostomy we damage the mucosa, as a permanent urethral catheter does in the posteriorurethra in the acute stages. The principle seems to me the same.

H. L. Frankel (G.B.). Mr. Chairman, it is with some trepidation that I would disagree with Sir Ludwig. First of all, I don't think a tracheotomy is analagous to a urethral catheter; I think it is analagous to a suprapubic catheter. Secondly, the tracheal sensation has been present in all these patients. Admittedly, the blood supply of the tracheal rings may have been impaired in the cervicals, but their actual sensation is present and normal: we are currently doing some research on tracheal sensation and we have found no abnormality between the high and the low lesions. However, I entirely agree that tracheostomies should not be done unnecessarily. Fortunately, all these four were absolutely imperative and decisive indications - they would not have survived if they had not had a tracheostomy. I agree that one can pass tubes from above without tracheostomy, I am not yet certain of how long or in what way they can be used. If one goes about this too enthusiastically I think we will transfer the site of our stricture and damage from the low part to the larynx, and this may eventually be an equally difficult problem. Certainly, for temporary use it is satisfactory, but we have not used it for more than 36 hours in adults.

Sir Ludwig GutTMANN. It is not so much the question whether the sensibility of the trachea in these high lesions is normal or not, although I would like to know details 
of your sensory tests. What you seem to have overlooked is that in the acute stage of the high lesion there is the paralytic vasodilation as the vasoconstrictors are paralysed, as you know, and that makes the changes in the tone of the trachea as it does in the urethra in more distal cord lesions. Hence the comparison with the pressure due to indwelling urethral catheter resulting in mucosal damage.

ChaIrman. Before we move on, perhaps I may have the privilege of throwing one last thought at this question. We've talked about the materials of which the tube are constituted, we've talked about the manner in which the balloon blows up, but we have not discussed the possibility of the endotracheal tube being dragged by the weight of the connecting tube, so that we are talking about a pressure sore between the end of the tube and the lumen of the trachea. Now, I think we've all been dissatisfied to see tubes dragging; even with safety pins and pillows and goodness knows what it still happens. I am sure this is familiar to many of you, but I do want to put this in. The Bennett Respiratory Company have recently produced a new model which incorporates an articulated arm between the body of the respirator and the end of the tube. And with this balanced articulated arm one can position and maintain one's tracheostomy tube centrally down the lumen. This could be yet another factor in the genesis of these lesions.

\title{
POSTURAL VARIATIONS OF THE CAPACITY IN TETRAPLEGICS
}

\author{
By J. V. Forner Valero, D.Phys.Med.(London) \\ Centro de Rehabilitacion y Traumatologia, \\ Ciudad Sanitaria 'La Fe', Valencia, Spain
}

\section{ABBREVIATED}

THIs short paper, 'A Study on Changes of Vital Capacity of the Lung by Changing the Patient's Position', was carried out in five patients with cervical injuries: one complete lesion below $\mathrm{C}_{4}$, one complete below $\mathrm{C}_{5}$, one complete below $\mathrm{C}_{6}$, one complete below $\mathrm{C}_{7}$ and two incomplete below C6. This is an important problem, as many of these patients have respiratory trouble and yet, on the other hand, have to be turned or put in different positions to avoid pressure sores.

Except in high cervical injuries with partial paralysis of the diaphragm there is no or little dyspnoea, unless respiratory infection is present. A simple bronchitis may kill a cervical patient, due to his inability to cough.

Method. To assess the influence of position on the ventilatory capacity of patients with cervical lesions, spirograms were carried out in various positions: supine, prone, lateral, head down and head up positions (the latter up to $45^{\circ}$ ).

Result. The values were found as low as $22 \cdot 2$ per cent. of normal values in the patient with $\mathrm{C}_{4}$ lesion in sitting position, and as high as 84.9 per cent. in the head-down position in the $\mathrm{C}_{7}$ lesion. The maximum mean value was found in the head-down position $(73.2$ per cent.) and the minimum in sitting position (49 per cent.). In the prone position, the values are much lower than in the supine position and the prone position is not a satisfactory position for tetraplegics with respiratory trouble. In fact, it should be avoided. In both lateral positions, the values found were similar to the value found in the supine position. Finally, the values of E.R.V. (expiratory reserve volume) are low, due to the absence of the expiratory muscles. 